\title{
Thermal Analysis on Hydroxyapatite Synthesis through Mechanochemical Method
}

\author{
A.S.F. Alqap ${ }^{1,3}$, S. Adzila ${ }^{2,4}$ I. Sopyan ${ }^{1}$, M. Hamdi ${ }^{2}$, and S. Ramesh ${ }^{2}$ \\ ${ }^{1}$ Department of Manufacturing and Materials Engineering, International Islamic University Malaysia, Kuala Lumpur, Malaysia \\ ${ }^{2}$ Department of Engineering Design and Manufacture, University of Malaya, Kuala Lumpur, Malaysia \\ ${ }^{3}$ Mechanical Engineering Program, University of Bengkulu, Bengkulu, Indonesia \\ ${ }^{4}$ Department of Material Engineering and Design, Universiti Tun Hussein Onn Malaysia, Johor, Malaysia
}

\begin{abstract}
Thermal analysis of hydroxyapatite formation through dry mechanochemical method has been studied. The calcium phosphate was synthesized using calcium hydroxide and di-ammonium hydrogen phosphate as the precursors. The ball milling of 1/6 ball-powder mass ratio was employed on mixtures of calcium hydroxide and di-ammonium hydrogen phosphate in three different speeds 170, 270 and $370 \mathrm{rpm}$ for $15 \mathrm{~h}$. As ball-milled powders were then sintered at 1150, 1250 and $1350^{\circ} \mathrm{C}$ for $2 \mathrm{~h}$, then subjected to TGA, XRD and FTIR for phase characterization. Calcium phosphates with ammonium are phases of the material. The ammonium is trace of phosphorus precursor. Choosing condition of the process and type of precursors determines type of reactions and its products.
\end{abstract}

Keywords - Heating, Milling, Hydroxyapatite, Calcium phosphate, Phase transformation.

\section{INTRODUCTION}

Hydroxyapatite (HA) is main concern of many works to develop a biomaterial for biomedical application. Many types of synthesis method have been performed for its production. One of them is mechanochemical process. Mechanical factor has been greatly involved in many synthesis processes where mechanical strength is as success key of phase transformation and chemical reactivity. In ceramic fields, the mechanical milling was proven successful to drive a chemical reaction to synthesize HA from calcium and phosphorus precursors either in dry $[1,2]$ or wet method [3-5]. Prolonged mechanical milling has induced amorphous phase transforming from $\beta$-TCP (tricalcium phosphate) that makes the new phase more soluble than the source phase and more feasible to produce biphasic phase containing $\beta$ TCP and HA after aging in a solution [6]. The mechanical factor also is involved to make calcium phosphate precursors more reactive for setting reaction [7]. Here the dry mechanical milling is attempted to synthesize HA from calcium and phosphorus precursors. Any phases as result of mechanically induced thermal reaction are discussed.

\section{Materials AND METHODS}

The mechanical milling is attempted on an objective to synthesize hydroxyapatite phase based on the reaction as follows

$5 \mathrm{Ca}(\mathrm{OH})_{2}+3\left(\mathrm{NH}_{4}\right)_{2} \mathrm{HPO}_{4} \rightarrow \mathrm{Ca}_{5}\left(\mathrm{PO}_{4}\right)_{3} \mathrm{OH}+6 \mathrm{NH}_{3}+9 \mathrm{H}_{2} \mathrm{O}$

Calcium hydroxide $\left(\mathrm{CH}, \mathrm{Ca}(\mathrm{OH})_{2}\right)$ and di-ammonium hydrogen phosphate $\left(\left(\mathrm{NH}_{4}\right)_{2} \mathrm{HPO}_{4}, \mathrm{DAP}\right)$ are commercially available of, respectively, R\&M Chemicals and Systerm. The planetary ball mill is performed to induce mechanical effect using a powder to ball mass ratio as $1 / 6$ for 15 hours of running and stopping with three different speeds; 170 , 270 and $370 \mathrm{rpm}$. Sintering is then given on the as-milled powders for different high temperatures 1150, 1250 and $1350^{\circ} \mathrm{C}$ for 2 hours with $5^{\circ} \mathrm{C} / \mathrm{min}$ heating and cooling rates. Phase characterizations are attempted by using of a Perkin Elmer Phyris Diamond TG-DTA of $10^{\circ} \mathrm{C} / \mathrm{min}$ heating rate to evaluate thermal stability, a Shimadzu XRD 6000 diffractometer at the range of $2 \theta=25-55^{\circ} \mathrm{C}$ and $2^{\circ} \mathrm{C} / \mathrm{min}$ scan speed to evaluate phases and a Perkin-Elmer Spectrum FTIR spectrometer of $4000-400 \mathrm{~cm}^{-1}$ scanning range with resolution of $4 \mathrm{~cm}^{-1}$ to evaluate the functional group of chemical bonding.

\section{Results}

Thermal characterization is important to know material reactivity under specific temperature. Different speed obviously affects weight loss and weight gain of the material under TGA test. TG and DTA tests divide the material into regions as detailed in Table 1 . How are the lines pattern in the regions of endo and exothermal and during weight gain and weight loss that observed from TGDTA tests are shown in Figure 1 and Figure 2. Phases that appear after thermal reaction are evaluated by XRD and the patterns are depicted in Figure 3. Finally, IR spectra that has been obtained to evaluate functional group of chemical bonding from FTIR characterization is given in Figure 4. 
Table 1 TGDTA tests divide material reactivity into areas of loss-gain in weight and Endo-Exothermal as well

\begin{tabular}{|c|c|c|c|c|c|c|}
\hline TGDTA rpm & $30-190^{\circ} \mathrm{C}(\mathrm{I})$ & $\begin{array}{c}190-400^{\circ} \mathrm{C} \\
\text { (II) }\end{array}$ & $\begin{array}{c}400-800^{\circ} \mathrm{C} \\
\text { (III) }\end{array}$ & $\begin{array}{c}800-1000^{\circ} \mathrm{C} \\
\text { (IV) }\end{array}$ & $1000-1100^{\circ} \mathrm{C}(\mathrm{V})$ & $1100-1300^{\circ} \mathrm{C}(\mathrm{VI})$ \\
\hline 170 (DTA) & Endo (-) & Go up to $(+)$ & $\begin{array}{l}\text { Continuous in } \\
\text { Exo }(+)\end{array}$ & $\begin{array}{l}\text { Still in }(+) \text { and } \\
\text { down to }(-)\end{array}$ & $\begin{array}{l}\text { Continuous in } \\
\text { Endo (-) }\end{array}$ & Go up to $(+)$ \\
\hline 270 (DTA) & As above & As above & As above & As above & As above & As above \\
\hline 370 (DTA) & As above & As above & As above & As above & As above & As above \\
\hline 170 (TGA) & Fast to $\mathrm{W} / \mathrm{L}$ & $\mathrm{W} / \mathrm{L}$ & $\mathrm{W} / \mathrm{L}$ & $\begin{array}{l}\mathrm{W} / \mathrm{G} \text { at } 900+ \\
\text { fast to } \mathrm{W} / \mathrm{L}\end{array}$ & $\mathrm{W} / \mathrm{L}+$ small $\mathrm{W} / \mathrm{G}$ & Go up to $\mathrm{W} / \mathrm{G}$ \\
\hline 270 (TGA) & Fast to $\mathrm{W} / \mathrm{L}$ & $\mathrm{W} / \mathrm{L}$ & $\begin{array}{c}\text { Jump to } \mathrm{W} / \mathrm{G} \\
\text { at } 600^{\circ} \mathrm{C}+ \\
\mathrm{W} / \mathrm{L} \text { with } \\
\text { fluctuation }\end{array}$ & $\begin{array}{l}\mathrm{W} / \mathrm{G} \text { at } 900^{\circ} \mathrm{C} \\
+ \text { fast to } \mathrm{W} / \mathrm{L}\end{array}$ & $\mathrm{W} / \mathrm{L}$ & A few $W / G$ \\
\hline 370 (TGA) & Fast to $\mathrm{W} / \mathrm{L}$ & $\mathrm{W} / \mathrm{L}$ & $\begin{array}{l}\text { W/L with } \\
\text { fluctuation }\end{array}$ & $\begin{array}{l}\mathrm{W} / \mathrm{G} \text { at } 900^{\circ} \mathrm{C} \\
+ \text { fast to } \mathrm{W} / \mathrm{L}\end{array}$ & $\mathrm{W} / \mathrm{L}$ & A few W/G \\
\hline
\end{tabular}

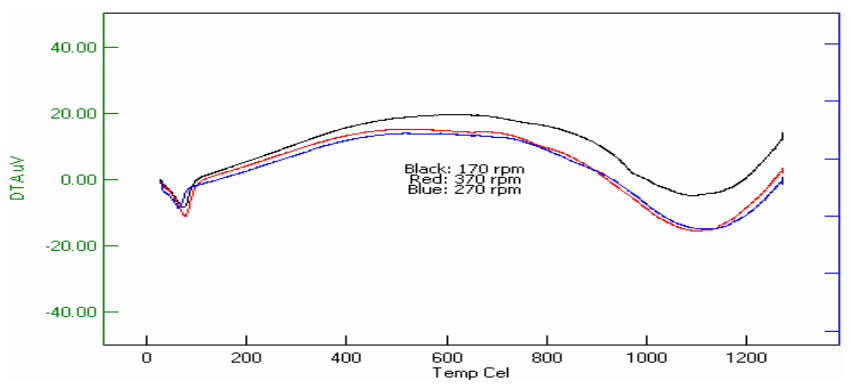

Fig. 1 DTA patterns of three samples of different speeds at $10^{\circ} \mathrm{C} / \mathrm{min}$ heating rate

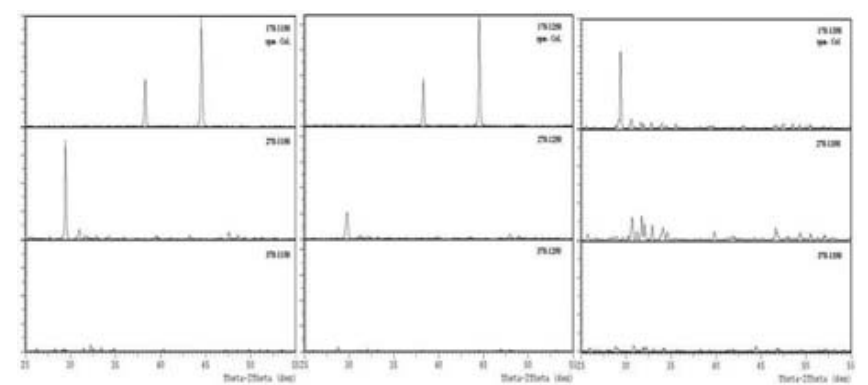

Fig. 3 The XRD tests of three different speeds: $170 \mathrm{rpm}$ (upper), $270 \mathrm{rpm}$ (middle), and $370 \mathrm{rpm}$ (lower) at three different heating temperatures: $1150^{\circ} \mathrm{C}$ (left), $1250^{\circ} \mathrm{C}$ (middle), and $1350{ }^{\circ} \mathrm{C}$ (right)

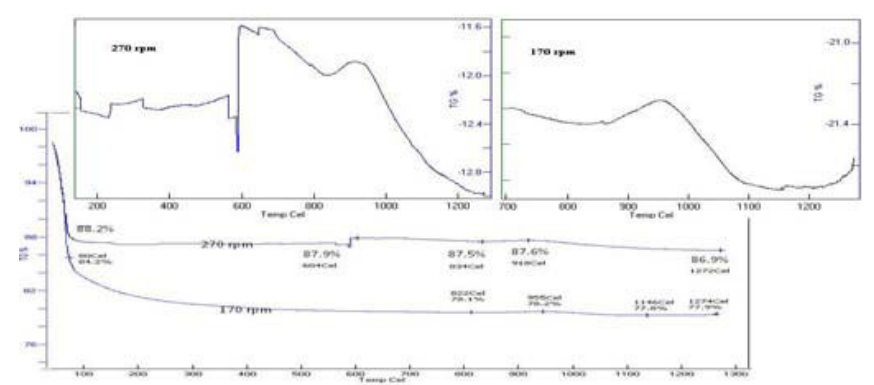

Fig. 2 The example of TGA patterns. The patterns are for the 270 and 170 rpm speed samples with the inset to high the scale
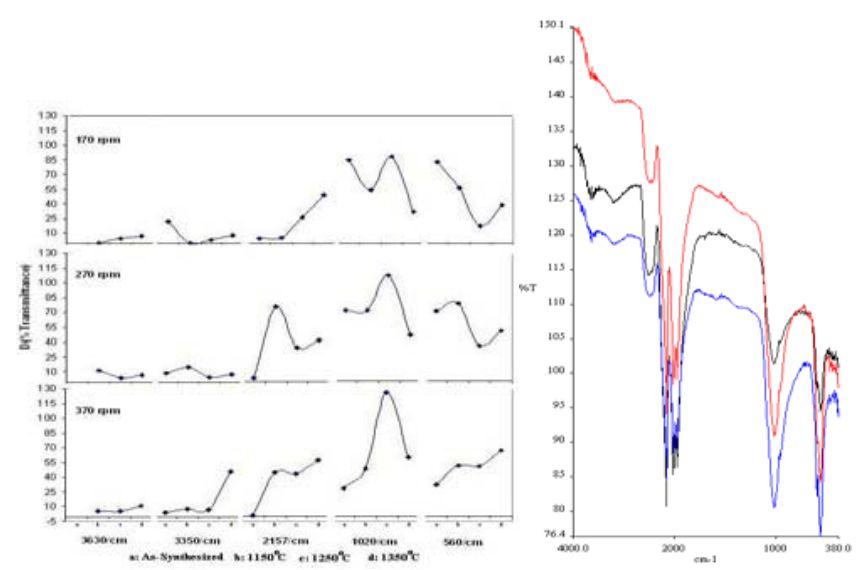

Fig. 4 The IR spectra test characterizes the appearance of certain element by its functional group with its transmittance percentage $(\% \mathrm{~T})$ showing the degree of intensity. The appearance intensity among available functional groups is comparable (left). The example of complete IR spectra is taken after 1350 heating. $170 \mathrm{rpm}$ black, $270 \mathrm{rpm}$ blue and $370 \mathrm{rpm}$ red (right) 


\section{Discussions}

In the region I (see Table 1) the sample heating reaction absorbs heating from its surrounding as result of decomposition of ADP and water evaporation as DTA records in negative region, i.e. endothermal, and accordingly TGA records as weight loss. All of the three speeds have similar condition at the region I where losing rate is tremendously high. The formation of calcium ammonium phosphate with water crystal, CaNH4PO4.6H2O (CAP), is possible at around $50^{\circ} \mathrm{C}$ only. By heating, the amount of water crystal decreases then the weight decreases. On the way of this heating DAP decomposes into ammonia $\left(\mathrm{NH}_{3}\right)$ and ammonium di-hydrogen phosphate (ADP). ADP then decomposes into $\mathrm{NH}_{3}$ and phosphoric acid. Then the phosphoric acid produces water and $\mathrm{H}_{4} \mathrm{P}_{2} \mathrm{O}_{7}$. From $\mathrm{H}_{4} \mathrm{P}_{2} \mathrm{O}_{7}, \mathrm{P}_{2} \mathrm{O}_{5}$ and water show up. This condition causes the system is rich of $\mathrm{Ca}^{2+}$, $\mathrm{OH}^{-}, \mathrm{NH}_{4}^{+}$, water crystal, $\mathrm{CaO}, \mathrm{HPO}_{4}{ }^{2-}$ and so variation of $\mathrm{H}-\mathrm{P}-\mathrm{O}$ and P-O ions on. Another work of ADP with calcium precursor in aqueous synthesis by Alqap and coworker [8] is worthy for comparison. In the region II, CAP decomposes to $\mathrm{CaHPO}_{4}$ and $\mathrm{NH}_{3}$. Then $\mathrm{CaHPO}_{4}$ transform to calcium pyrophosphate (CPP) with constitutional water. This stage causes the region II going to weight gain gradually, accordingly DTA records as going to positive region, i.e. exothermal region. The gradual increase is because the formation of the new crystal is followed by dehydration of crystal water. Slow down in dehydration rate makes the slope of increment steeper and slower in the range of $400-600^{\circ} \mathrm{C}$. In the region III, the DTA reaction is being continuously at positive or exothermal region. In the range of $600-700^{\circ} \mathrm{C}$ the formation of calcium pyrophosphate is still possible (see Figure 2). The formation of the new phase does not significantly happen for the 170 and $370 \mathrm{rpm}$ speeds. They show only very tiny increase in gradual manner. This is not as the $270 \mathrm{rpm}$ speed that suddenly jumps to increase its weight by $1 \%$. The fluctuation in weight gain and weight loss is observed at those samples in further way. In between $700-800^{\circ} \mathrm{C}$, a formation of amorphous apatite is possible. This formation with very tiny weight gain before $800^{\circ} \mathrm{C}$ is observed. In the region IV, especially at $900^{\circ} \mathrm{C}$, all the samples have weight gain before they go to lose their weight again. Here HA forms. In the region V, HA gradually decompose into $\beta$ TCP. This decomposition that observed as faster to $1100^{\circ} \mathrm{C}$ and gradually slower further is interesting. Difference density between HA and $\beta$ TCP is only around 0.08 while between $\beta$ TCP and $\alpha$ TCP around 0.3 $\mathrm{g} / \mathrm{cm} 3$. It should be other reason to explain this phenomenon. In the region VI, the $170 \mathrm{rpm}$ sample inclines direction from weight loss to weight gain at $1200^{\circ} \mathrm{C}$, while the two others continuously lose the weight but a few jump in weight at the end (see Figure 2). These weight gains accordingly are recorded as inclination point from endo to exothermal by DTA. This explains that there should be a formation of new crystal takes place.

XRD characterization shows that the $170 \mathrm{rpm}$ speed gives two major peaks after 1150 and $1250^{\circ} \mathrm{C}$ heating at $38.3^{\circ}$ and $44.5^{\circ} 2 \theta$, and after $1350^{\circ} \mathrm{C}$ heating at $29.5^{\circ}$ which is followed by minor peaks at $30.5^{\circ}, 31.5^{\circ}, 32^{\circ}$ and so on. The $270 \mathrm{rpm}$ speed gives one major peak $29.5^{\circ}$ after $1150^{\circ} \mathrm{C}$ heating, minor peaks at $31^{\circ}, 31.7^{\circ}$ and so on. In the next heating, $1250^{\circ} \mathrm{C}$, these peaks are reduced in intensity. After $1350^{\circ} \mathrm{C}$ heating, the major peak disappears while the minor peaks become significant, i.e., at $30.5^{\circ}, 31.3^{\circ}, 31.7^{\circ}$ and so on. The $370 \mathrm{rpm}$ speed delineates all the major peaks and the minor peaks become the characteristic peaks of the sample but still with tiny peaks. After $1150^{\circ} \mathrm{C}$ heating peaks of $31.5^{\circ}, 32^{\circ}$ and so on appear. The same appearance is also after 1250 and $1350^{\circ} \mathrm{C}$, however the intensity of the $1250^{\circ} \mathrm{C}$ heating is small. The major peaks at $29.5^{\circ}, 38.3^{\circ}$ and $44.5^{\circ}$ may belong to ADP which as pure component has characteristic peaks at $29^{\circ}, 33.3^{\circ}, 37.5^{\circ}$ and $45^{\circ}$. The minor peaks can be counted at $29.5^{\circ} 2 \theta$ as $\mathrm{CPP}\left(29.55^{\circ}\right), \mathrm{CaHPO}_{4} \cdot 2 \mathrm{H}_{2} \mathrm{O}$, DCPD $\left(29.5^{\circ}\right)$, or $\mathrm{CaPO}_{3}(\mathrm{OH}) .2 \mathrm{H}_{2} \mathrm{O}, \mathrm{CPH}\left(29.3^{\circ}\right)$, at $30.5^{\circ}$ as $\alpha$-TCP $\left(30.8^{\circ}\right)$, at $31^{\circ}$ as $\beta$-TCP and at $31.7^{\circ}$ as HA. (JCPDS cards: CPP \# 33-297, DCPD \#2-85, CPH \#9-77, $\beta$-TCP \#9-169, $\alpha$-TCP \#9-348, HA \#9-432).

The minor of the calcium phosphate phases with the major appearance of ADP is very interesting. The minor and major appearance suggests that the former is possibly coated by the later, or because the former is crystalline while the later is amorphous. From XRD, the recovery of weight at $>1100^{\circ} \mathrm{C}$ of TGA test is possible by the formation of N-H structure.

FTIR test show the pattern as shown in Figure 4. The main peaks that appear in the IR spectra [9] are mainly at $3630 / \mathrm{cm}$ region and its surrounding for $\mathrm{O}-\mathrm{H}$ and $\mathrm{N}-\mathrm{H}$, $3350 / \mathrm{cm}$ region and its surrounding for $\mathrm{N}-\mathrm{H}$ or $\mathrm{C}-\mathrm{H}$, $2157 / \mathrm{cm}$ region and below for $\mathrm{N}-\mathrm{H}, \mathrm{C}-\mathrm{O}, \mathrm{C}-\mathrm{N}$ or $\mathrm{N}-\mathrm{O}$, $1020 / \mathrm{cm}$ region and surrounding for $\mathrm{P}-\mathrm{O}$ and $560 / \mathrm{cm}$ region and surrounding for P-O also. Using D(\% Transmittance) that is different between $\% \mathrm{~T}$ point initially starts at $4000 / \mathrm{cm}$ and $\% \mathrm{~T}$ point at a characteristic peak of the wave number mentioned earlier, the degree of intensity is depicted in the left of Figure 4. At all of the three speeds, O-H as water molecule appears after synthesis (the figure is not shown here), but not after heating. After three heatings $\mathrm{O}-\mathrm{H}$ of crystal is observed. The $\mathrm{O}-\mathrm{H}$ as crystal interestingly increases with heating temperature increases. It suggests that the increase in heating temperature may exert crystal water in the particle as contribution of products of many reactions above discussed. However, the $270 \mathrm{rpm}$ speed at $1250^{\circ} \mathrm{C}$ heating has the lowest in the crystal water (see Figure 4 at left). The 3350 and $2157 / \mathrm{cm}$ regions confirm 
the appearance of $\mathrm{N}-\mathrm{H}$ functional bonding systems. $\mathrm{C}$ and $\mathrm{O}$ that may come from the air during milling can be neglected here because the system is sealed. The $3350 / \mathrm{cm}$ significantly increase for the $370 \mathrm{rpm}$ speed after $1350^{\circ} \mathrm{C}$ heating. The $2157 / \mathrm{cm}$ region is strengthened by heating not by speed. The $1020 / \mathrm{cm}$ region is strengthened by speed and by heating, especially at 1250 . The region of 560 is reduced by speed, but the 370 speed strengthens the region. The 3350 and the $2157 / \mathrm{cm}$ peaks strengthen each other such N$\mathrm{H}$ structure significantly appear and compete with the orthophosphate peaks, i.e. 1020 and $560 / \mathrm{cm}$ regions (see Figure 4). The N-H does not appear significantly in either the range of $3300-2800 / \mathrm{cm}$ or $1456-1400 / \mathrm{cm}$ as Salas et al found [10], it may be the condition there and here are different like that people found carbonate systems in different regions between dry and wet processes.

The increase in speed increases the intensity of $1020 / \mathrm{cm}$ region, however, it is true if the sample is heated at $1250^{\circ} \mathrm{C}$. Among three speeds and three heatings the 270 speed and $1350^{\circ} \mathrm{C}$ heating gives better appearance of calcium phosphate. Indeed, the continuous heating drives the phase transformation takes place from a non stable phase to more stable. The dry condition, however, maintains some traces keeping in touch with the particles. In further cooling these traces transform to form the complex structure like calcium ammonia ortho- phosphate. The above facts suggest that dry process supports the appearance of $\mathrm{NH}_{3}$ instead of $\mathrm{NH}_{4} \mathrm{OH}$. $\mathrm{NH}_{4} \mathrm{OH}$ appears because $\mathrm{NH}_{3}$ reaction of the phosphorus precursor with water in a aqueous system. This $\mathrm{NH}_{4} \mathrm{OH}$ is responsible to cause the formation of hydroxyapatite success in such a way that water washes out ammonium from phosphorus precursor and exert a condition such conducive that hydroxyapatite formation takes place. In dry condition the situation is much different. Mobility of particle is more limited, once the particle sticks on the wall or the ball then no more mobility is expected, hence, the reactivity now fully depends on heating and the mass ratio of ball and particle. However, the condition is not fulfilled enough by the heating and mass ratio. There is another factor affecting reaction products at the end, that is physical properties of precursors such as hygroscopic, wettability, melting, boiling and polymerization that could affect condition of the reaction and its steps advance as this work has found out it here.

\section{Conclusions}

The dry milling process involving calcium hydroxide and di-ammonium hydrogen phosphate (DAP) has been employed to produce calcium phosphate powders. Three different conditions of speed and heating have shown their effects on the phase transformation. The characterization revealed that the calcium phosphate phases appear with ammonia trace remained from phosphorus precursors.

\section{ACKNOWLEDGEMENT}

The authors are grateful to Biomedical Engineering Research Group of International Islamic University Malaysia (IIUM) for supporting this research.

\section{REFERENCES}

1. Nasiri-Tabrizi, B., P. Honarmandi, R. Ebrahimi-Kahrizsangi, and P. Honarmandi (2009) Synthesis of nanosize single-crystal hydroxyapatite via mechanochemical method. Materials Letters 65:543-546.

2. Silva, C.C., A.G. Pinheiro, M.A.R. Miranda, J.C. Góes, and A.S.B. Sombra (2003) Structural properties of hydroxyapatite obtained by mechanosynthesis. Solid State Sciences 5:553-558.

3. Yeong, K.C.B.W., J.Ng, S. C. (2001) Mechanochemical synthesis of nanocrystalline hydroxyapatite from $\mathrm{CaO}$ and $\mathrm{CaHPO} 4$. Biomaterials 22: $2705-2712$.

4. Mostafa, N.Y.(2005) Characterization, thermal stability and sintering of hydroxyapatite powders prepared by different routes. Materials Chemistry and Physics 94:333-341.

5. Rhee, S.-H.(2002) Synthesis of hydroxyapatite via mechanochemical treatment. Biomaterials 23:1147-1152.

6. Gburecka, U., Grolms, O., Barralet, J.E., Grover, L.M., Thull, R.(2003) Mechanical activation and cement formation of b-tricalcium phosphate. Biomaterials 24:4123-4131.

7. Song, Y., Feng, Z., Wang, T.(2007) In situ study on the curing process of calcium phosphate bone cement. Journal of Material Sciences: Materials in Medicine 18:1185-1193.

8. Alqap, A.S.F., Sopyan, I.(2009) Low temperature hydrothermal synthesis of calcium phosphate ceramics: effect of excess $\mathrm{Ca}$ precursor on phase behaviour. Indian Journal of Chemistry 48A: 1492-1500.

9. Smith, B. (1999) Infrared spectral interpretation, a systematic approach. CRC Press, Boca Raton.

10. Salas, J., Benzo, Z., Gonzalez, G., Marcano, E., Gomez, C. (2009) Effec of $\mathrm{Ca} / \mathrm{P}$ ratio and milling material on the mechanical preparation of hydroxyapatite. Journal of Material Sciences: Materials in Medicine 20:2249-2257.

Corresponding Author:

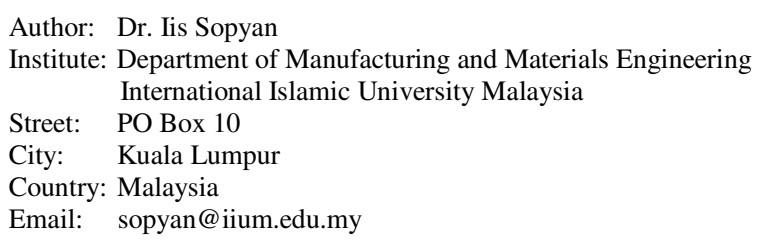

